\title{
Survival Analysis of Persons Involved in Road Accidents in National Capital Region
}

\author{
Franz Jeremiah G. Ibay ${ }^{1}$, Kathleen Jaeight N. de Guzman², Sherilyn G. Escobar ${ }^{3}$, Bernadeth G. \\ Nobles $^{2}$ and Audie B. Oliquino ${ }^{2}$
}

\author{
'Department of Mathematics, Lagro High School; ibay.franzjeremiahg@gmail.com \\ ${ }^{2}$ Department of Mathematics and Statistics, College of Science, Polytechnic University of the Philippines - Manila; \\ jaeightdg@yahoo.com, bgnobles_pupcs@yahoo.com, aboliquino@pup.edu.ph \\ 32Department of Mathematics, Kaypian National High School, Bulacan; sherilyn.escobar@deped.gov.ph
}

\begin{abstract}
Objective: This study delivers a survival analysis of persons involved in road accidents in National Capital Region. Methods/ Analysis: The data were obtained from the Metropolitan Manila Development Authority (MMDA) through Metro Manila Accident Recording and Analysis System (MMARAS) program from January 2012 - June 2017 with respect to time $t$ (day of the accident), and covariates age, gender, weather, time period, location, accident factor, vehicle, junction type, junction control, collision type, and the death of a person involved in a road accident, under Cox Regression and Kaplan-Meier Estimates. Findings: Through the study, the researchers found out that out of 42,877 persons involved, only 962 persons or 2.24\% died, and most of the people counted in are male which implies that men have greater risk of death than women. The probability risk was given the equation, where is the survival function, is the cumulative hazard function which was determined with use of Cox Regression. Application/Improvements: For the government, this research can be used to monitor road accidents and can be a basis on planning seminars for the drivers related to road safety. For the citizens, this can be utilized to give awareness on several events related to road accidents. This study will be more useful if the available data would be more updated, and for each accident, all details will be recorded.
\end{abstract}

Keywords: Cox Regression, Kaplan-Meier Estimation, Road Accidents, Survival Analysis, Traffic

\section{Introduction}

In 2017, the World Health Organization (WHO) 1 mentioned that in a year, greater than 1.25 million die around the globe because of road accidents and without any action to this, road accidents could become the seventh leading reason of death by 2030. In the same year, the Philippine Star cited Philippine Statistics Authority (PSA)'s data which showed that 34 Filipinos are dying every day in road accidents $\mathrm{s}^{2}$ even though there are a lot of road safety national laws enacted in the country such as Car Seatbelts (RA 8750) $)^{3}$, Motorcycle Helmets (RA 10054) $)^{4}$, Speed Limit (RA 4136)
Drugged Driving (RA 10586) ${ }^{6}$, and the most recent, the Anti-Distracted Driving Law (RA 10913) ${ }^{7}$.

A road accident refers to any action involving at least one road vehicle, occurring on a road open to public, and in which at least one person is injured or killed. Acts with the intention of murder, suicide, operational disasters are excluded. This kind of accident becomes a casual thing in the everyday lives of the people wherein it is in the news on the television, radio, and in the social media. Due to that, most of them neglect this and disregards the risks involved in their driving and due to that, accident occurs.

Based on the data collated by the Metropolitan Manila Development Authority (MMDA) for the National Capital 
Region, through its Metro Manila Accident Recording and Analysis System (MMARAS) program $\stackrel{8}{*}$, the number of vehicular accidents rose in 2016 by 13,707 to 109,322 from the 95,615 the previous year where 16,416 were injured and worst, 426 people died in road accidents. It can be grasped that as the years pass, the number of vehicular accidents increases.

According to formerly known Department of Transportation and Communications (DOTC) ${ }^{9}$ now Department of Transportation (DOT), there is a rise of $14.6 \%$ to the number of deaths due to road accidents each year where $79 \%$ is caused by driver's error, and $11 \%$ because of defective vehicle condition.

However, this increase stated in the number of accidents is not valid to generalize about the state of the road accidents. Thus, we need to study these data statistically. In this study, the researchers consider road accidents and its impact on human lives and properties in the Philippines' National Capital Region.

The National Capital Region (NCR) is composed of 17 local government units (LGUs) of 16 cities: Caloocan, Malabon, Navotas, Valenzuela, Quezon City, Marikina, Pasig, Taguig, Makati, Manila, Mandaluyong, San Juan, Pasay, Paranaque, Las Pinas and Muntinlupa, and one municipality: Pateros. Each LGU in Metro Manila is headed by a Mayor. According to Philippine Statistics Authority (PSA) under its Census of Population ${ }^{10}$, the total population of the region as of August 1, 2015 was 12.89 million with a growing rate of $1.78 \%$ in the period 2010-2015. Also, $12.8 \%$ of the population is in Metro Manila.

Some researchers have modeled several types of mathematical models about road accidents worldwide: the vehicle type involved in Metro Manila ${ }^{11}$ severity and duration of a road accident in Shanghai ${ }^{\frac{12}{2}}$, and survival of a person in a road accident in Ghana ${ }^{13}$ but we cannot apply some of these models in the Philippines because of the difference in the factors of their respective countries that are not applicable to the country. Few researchers attempt to have statistical research about road accidents in the Philippines due to limited information available about it. One is the article entitled "A Logistic Regression Analysis on the Influence of Accident Factors on the Fatalities of Road Accidents in Metro Manila", where a total of 29,409 accidents were studied after tallying all the accidents with the complete information on all the considered factors such as age, gender, junction type, weather, location, time and vehicle type are the independent variables. The model formulated in this study shows the relationship of the dependent variable and the significant factors in terms of odds-ratio concept. The findings show that all the independent variables except for age are statistically significant in the accident fatality of road accidents from 2006 to $2016^{14}$.

The Metropolitan Manila Development Authority (MMDA) for the National Capital Region, through its Metro Manila Accident Recording and Analysis System (MMARAS) program has been releasing reports on the statistics on road accidents in the past years. In these reports, these factors include to possible contributors of the death of persons involved in road accidents. These factors include age, gender, time period of accident, location, type of vehicle, junction type, junction control, weather, and collision type. However, even though there are factors identified by the agency, nobody has modeled the death and survival of the persons involved, and the probability that the person will die and survive a road accident with the given factors.

\subsection{Research Paradigm}

The researchers used the Input-Process-Output model, a functional graph that determines the inputs, processes required and the outputs $\frac{15}{}$. It serves as a guide in analyzing the survival analysis of the persons involved in vehicular accidents in National Capital Region.

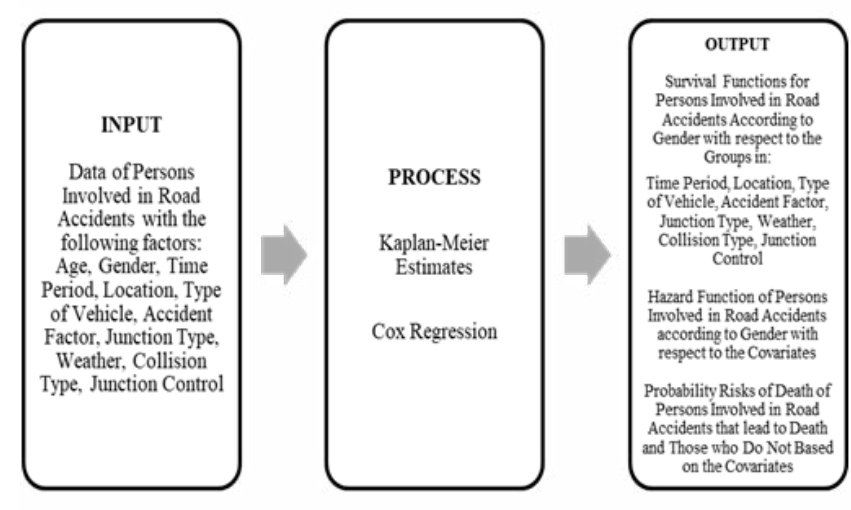

Figure 1. Research Paradigm.

The researchers input the data of the persons having the said factors, used two main processes: Kaplan-Meier Estimates, and Cox Regression. The survival functions for the persons involved in road accidents, the probability risks, the survival functions and the hazard functions of persons involved in road accidents with the factors are outputs that are expected. 


\subsection{Statement of the Problem}

To achieve the objective of the study, the researchers need to answer the following questions:

- What is the risk profile of the persons involved in terms of:

- Age;

- Gender;

- Time period;

- Location;

- Type of vehicle;

- Accident factor;

- Junction type;

- Weather;

- Collision type; and

- Junction control?

- What are the survival functions of persons involved in road accidents according to gender with respect to the groups in:

- Time period;

- Location;

- Type of vehicle;

- Accident factor;

- Junction type;

- Weather;

- Collision type; and

- Junction control?

- What is the hazard function of persons involved in road accidents with respect to the covariates?

- What are the probability risks of death of persons involved in road accidents based on the covariates?

\subsection{Scope and Limitations}

A total of 42,877 observations and ten variables were used in this research, wherein the vehicular accidents happened in NCR from January 2012 to June 2017 with the following factors: age, gender, time period of accident: ante meridiem (A.M.) or post meridiem (P.M.), location which is divided into districts: Central District - Quezon City, Eastern District - Mandaluyong, Marikina, San Juan, and Pasig, Northern District - Caloocan, Malabon, Navotas, and Valenzuela, Western District - Manila; Southern - Las Pinas, Makati, Muntinlupa, Paranaque, Pasay, Pateros, and Taguig, type of vehicle: bike, motor, tricycle, fx or taxi, bus, van, truck, and unknown vehicle (unidentified vehicles), accident factor: human error, vehicle defect, others (slippery roads, run over a stone, road defect, etc.) or none, junction type: K-junction, T-junction, Y-junction,
Rotunda, U-turn slot, cross roads, others (bridge, parking area, tunnel, underpass, etc.) or not at junction, junction control: traffic lights, school zone or none, weather: rain or fair, and collision type: angle impact, head on, rear-end, side swipe, self-accident, hit and run, hit object, hit parked vehicle, hit pedestrian, multiple collision, others (combination of two or more types of collision type) or none. The data needed for this study were obtained from Metro Manila Development Authority-Metro Manila Accident Recording and Analysis System (MMDA-MMARAS).

\section{Method}

This section includes the description of the data gathered, statistical treatments or methods used in this study in order to attain the main purpose of this paper.

\subsection{Data Gathering Procedure}

In this study, all of the data were obtained from the Metro Manila Development Authority through its program, Metro Manila Accident Recording and Analysis System (MMARAS). The researchers sent a formal letter of request to their good office on August 9, 2017. It was also stated in the letter that the data will be used in the study confidentially. The data was verified also.

\subsection{Kaplan-Meier Estimation}

The Kaplan-Meier Estimation is a non-parametric survival analysis tool utilized to approximate the two survival probabilities curves that deals with different times of survival particularly when some of the subjects do not continue in the study. The following are the assumptions of KaplanMeier Estimation: all subjects are results of random sampling from the population which means they are independent; the individuals which are censored have the same view of survival like those who continue in the study; this observations are cannot be examined and may make way to partiality that reduces $S$ artificially; the Kaplan-Meier survival estimate has a sense that at each unique time of survival, the step function changes except during the times of censoring (unless a time of survival occurs together with the time of censoring); and the examined event happens at a time which is precise. The late listing of the event examined usually cause false inflation of $S^{16,17}$. 


\subsection{Cox Regression}

Cox regression is a non-parametric tool used for examining the possible effects of different variables during the time a specified event occur. The general hazard function is defined by a baseline hazard function scaled by another function which is the model's (time-independent) covariates. In terms of the hazard model formula, it is written as

$$
H(t, X)=\left[h_{0}(t)\right] e^{\sum_{i=1}^{n} \beta_{i} X_{i}} .
$$

One of the significant features of this formula which is related to the assumption of the proportional hazards is that the baseline hazard is a function of $t$, but $X$ is excluded. On the other hand, the shown exponential expression includes the $X$ 's, but $t$ is excluded. The $X$ 's here are called time-independent $X$ 's, and $\beta$ 's are the coefficients of the covariates ${ }^{15}$.

\subsection{Probability Risks}

The risk of dying in a road accident is given by

$$
R(X, \text { Death })=1-e^{-H(t, X)}
$$

where $e^{-H(t, X)}$ is the survival function with respect to its cumulative hazard function $H(t, X)$, given by Cox Regression $\frac{16-17}{}$.

\section{Results and Discussions}

\subsection{Risk Profile of Persons Involved in Road Accidents in National Capital Region}

The risk profile of 42,877 persons involved in road accidents in National Capital Region. Out of this number, only 962 persons (2.24\%) led to death.

As for the gender, majority of the persons involved in these vehicular accidents are male, which is about $77.71 \%$ or 32,573 of the survivors and $88.77 \%$ or 854 of those instances that died. Moreover, female persons involved were only limited to $22.29 \%$ of those who survived and $11.23 \%$ of those who died. It can be implied that male drivers and passengers were more prone to accident than female due to the fact that most of the drivers were male.

According to age, notice that the ages from 20 to 29 years old were more prone to road accidents. This is almost similar to the report of Philippine Statistics Authority (PSA) cited in Rappler ${ }^{18}$ where the most frequent victims of road crashes between 2006 and 2015 in the Philippines are those who belong the age group of 20-24 years old. On the other hand, the age brackets with less number of involvements of persons in vehicular accidents were the following: 0 to 9,70 to 79,80 to 89 , and 90 to 99 years old, therefore this age brackets tends to be less likely prone to vehicular accidents. These findings on age can be attributed to the experience and the maturity that older drivers have in comparison to the younger drivers ${ }^{19}$.

In time periods, $54 \%$ of the persons who survived were in PM, and having almost the same percentage of the persons who died was in AM.

Regarding the location, Central District, which involves Quezon City, had the greatest number of accidents within Metro Manila, comprising 35\% of the overall number of road accidents, followed by the Southern District having $31.60 \%$ and $28.17 \%$ in those who survive and those who do not. In an article entitled "Mathematical Modelling of Road Accidents in Metro Manila ${ }^{11}$ ", it is also stated there that Quezon City is the place where accidents occur mostly due to its biggest land area among the cities in Metro Manila.

On the type of vehicle, it can be seen that almost 70\% of the persons involved are using motorcycle which supports the fact that this type of vehicle is one of the major reasons of accidents and deaths worldwide specifically in Brazil $^{20,21}$, Ghana ${ }^{22}$, in United States ${ }^{23}$, and in Europe ${ }^{24}$.

For the accident factor, majority of the events have no recorded accident factor, followed by the human error. On the other hand, others and vehicle defect had only a small portion of the accidents. In junction types, most of the time, the accidents happened not in junction or in an intersection, while the other junction types such as cross roads, K-junction, T-junction, Y-junction, U-turn slot and rotundas have only small numbers of accidents. With regards to weather, it can be observed that almost $99 \%$ of the time, the accidents happen in a fair weather and the remaining $1 \%$ is what the rain weather covers in the number of accidents. It can also be noticed that not having collision has the greatest number of cases covering $47 \%$ and $40 \%$ respectively to the cases of death and alive in road accidents. Lastly, accidents that have no junction control have the greatest percentage of the accidents happened garnering $97 \%$. 
Table 1. Risk Profile of Persons Involved in Road Accidents in National Capital Region

\begin{tabular}{|c|c|c|c|c|}
\hline & Alive & Percentage & \begin{tabular}{|l|} 
Died \\
\end{tabular} & Percentage \\
\hline & 41915 & 97.76 & 962 & 2.24 \\
\hline \multicolumn{5}{|l|}{ Gender } \\
\hline Male & 32573 & 77.71 & 854 & 88.77 \\
\hline Female & 9342 & 22.29 & 108 & 11.23 \\
\hline \multicolumn{5}{|l|}{ Age } \\
\hline $0-9$ & 554 & 1.32 & 8 & 0.83 \\
\hline $10-19$ & 2852 & 6.80 & 74 & 7.69 \\
\hline $20-29$ & 14361 & 34.26 & 302 & 31.39 \\
\hline $30-39$ & 12438 & 29.67 & 262 & 27.23 \\
\hline $40-49$ & 6781 & 16.18 & 161 & 16.74 \\
\hline $50-59$ & 3393 & 8.09 & 99 & 10.29 \\
\hline $60-69$ & 1209 & 2.88 & 40 & 4.16 \\
\hline $70-79$ & 267 & 0.64 & 13 & 1.35 \\
\hline $80-89$ & 56 & 0.13 & 3 & 0.31 \\
\hline $90-99$ & 4 & 0.01 & 0 & 0.00 \\
\hline \multicolumn{5}{|l|}{ Time Period } \\
\hline $\mathrm{AM}$ & 19437 & 46.37 & 513 & 53.33 \\
\hline $\mathrm{PM}$ & 22478 & 53.63 & 449 & 46.67 \\
\hline \multicolumn{5}{|l|}{ Location } \\
\hline Central & 14984 & 35.75 & 339 & 35.24 \\
\hline Eastern & 5823 & 13.89 & 118 & 12.27 \\
\hline Northern & 7198 & 17.17 & 194 & 20.17 \\
\hline Southern & 13246 & 31.60 & 271 & 28.17 \\
\hline Western & 664 & 1.58 & 40 & 4.16 \\
\hline \multicolumn{5}{|l|}{ Type of Vehicle } \\
\hline Bike & 3290 & 7.85 & 76 & 7.90 \\
\hline Motorcycle & 28704 & 68.48 & 669 & 69.54 \\
\hline Tricycle & 2517 & 6.01 & 43 & 4.47 \\
\hline Car & 3930 & 9.38 & 79 & 8.21 \\
\hline Jeep & 1746 & 4.17 & 35 & 3.64 \\
\hline Fx/Taxi & 440 & 1.05 & 5 & 0.52 \\
\hline Bus & 613 & 1.46 & 11 & 1.14 \\
\hline Van & 296 & 0.71 & 19 & 1.98 \\
\hline Truck & 204 & 0.49 & 16 & 1.66 \\
\hline Unknown & 175 & 0.42 & 9 & 0.94 \\
\hline \multicolumn{5}{|l|}{ Accident Factor } \\
\hline No Accident Factor & 39076 & 93.23 & 889 & 92.41 \\
\hline Human Error & 2742 & 6.54 & 67 & 6.96 \\
\hline Others & 34 & 0.08 & 4 & 0.42 \\
\hline Vehicle Defect & 63 & 0.15 & 2 & 0.21 \\
\hline \multicolumn{5}{|l|}{ Junction Type } \\
\hline Not at Junction & 39582 & 94.43 & 907 & 94.28 \\
\hline Cross Roads & 840 & 2.00 & 17 & 1.77 \\
\hline K-Junction & 3 & 0.01 & 0 & 0.00 \\
\hline T-Junction & 627 & 1.50 & 20 & 2.08 \\
\hline Y-Junction & 9 & 0.02 & 1 & 0.10 \\
\hline U-Turn Slot & 363 & 0.87 & 5 & 0.52 \\
\hline Rotunda & 248 & 0.59 & 2 & 0.21 \\
\hline Others & 243 & 0.58 & 10 & 1.04 \\
\hline \multicolumn{5}{|l|}{ Weather } \\
\hline Fair & 41432 & 98.85 & 949 & 98.65 \\
\hline Rain & 483 & 1.15 & 13 & 1.35 \\
\hline \multicolumn{5}{|l|}{ Collision Type } \\
\hline No Collision Type & 19417 & 46.32 & 389 & 40.44 \\
\hline Angle Impact & 3460 & 8.25 & 49 & 5.09 \\
\hline Head-On & 821 & 1.96 & 32 & 3.33 \\
\hline Rear-End & 4791 & 11.43 & 71 & 7.38 \\
\hline Side Swipe & 5988 & 14.29 & 88 & 9.15 \\
\hline Self-Accident & 1968 & 4.70 & 121 & 12.58 \\
\hline Hit and Run & 1912 & 4.56 & 41 & 4.26 \\
\hline Hit Object & 842 & 2.01 & 72 & 7.48 \\
\hline Hit Parked Vehicle & 219 & 0.52 & 4 & 0.42 \\
\hline Hit Pedestrian & 538 & 1.28 & 23 & 2.39 \\
\hline Multiple Collision & 1259 & 3.00 & 37 & 3.85 \\
\hline Others & 700 & 1.67 & 35 & 3.64 \\
\hline \multicolumn{5}{|l|}{ Junction Control } \\
\hline None & 40922 & 97.63 & 937 & 97.40 \\
\hline Traffic Lights & 941 & 2.25 & 25 & 2.60 \\
\hline School Zone & 52 & 0.12 & 0 & 0.00 \\
\hline
\end{tabular}

\subsection{Survival Functions of Persons Involved} in Road Accidents According to Gender with Respect to the Groups to each Covariate using Kaplan-Meier Estimates

\subsubsection{Time Period}

Figure 1 and 2 shows the survival functions of persons involved in road accidents according to gender with respect to time period. It can be seen that both male and female have high survival rates. For long-time observation, it shows that women have the higher survival chances than male during AM but on the other hand, they have the lower survival chances during PM.
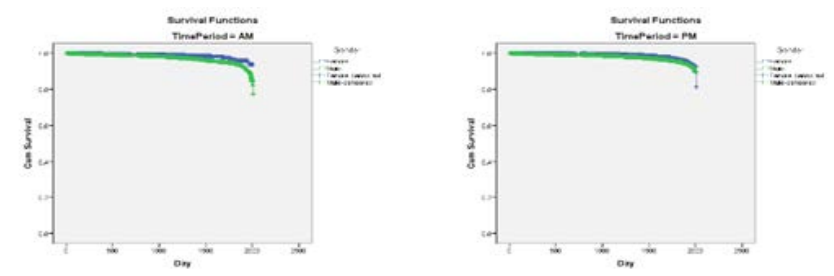

Figure 2. Survival Functions according to Gender Groups with Respect to Time Period.
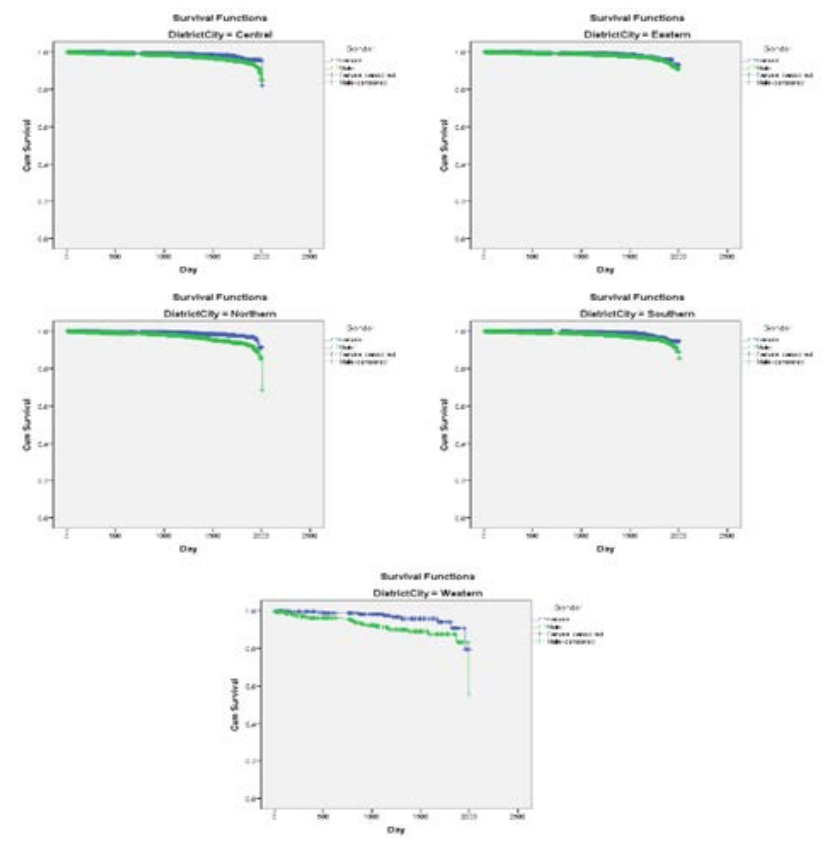

Figure 3. Survival Functions according to Gender Groups with Respect to Location. 


\subsubsection{Location}

As shown in Figure 3, both male and female have high survival chances when involved in vehicular accident with respect to its location. Also, it can be seen that as a road accident occurs at Eastern, Northern, Southern, and Western Districts, women have high survival chances than men. However, the survival chances of females decreased on the latter part of the observation period in Northern District, implying that males can survive higher than females if the vehicular accident happens in Northern District.
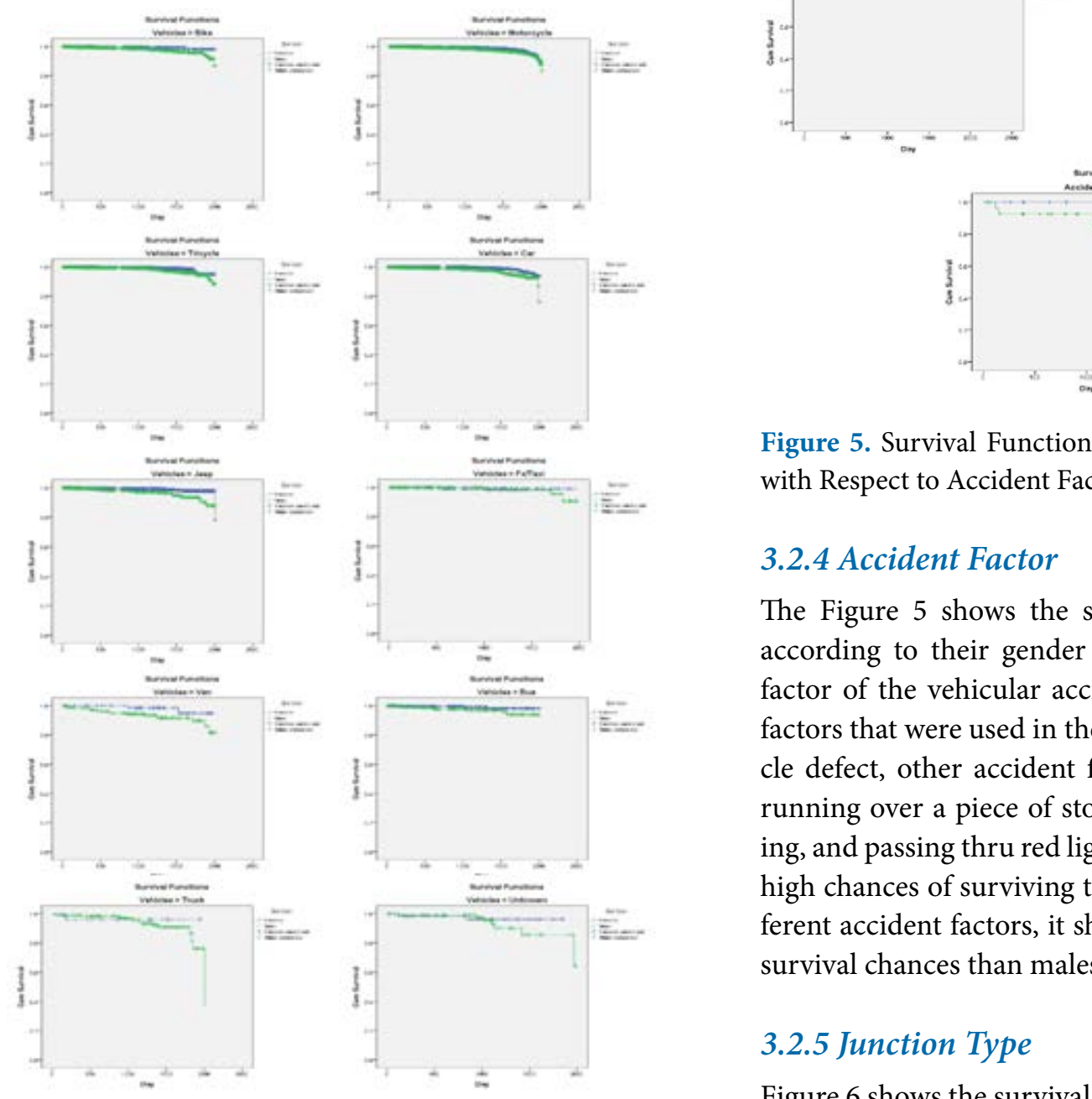

study's time frame, it shows that females have high survival chances than males if the vehicle involved in the accident is bike, motorcycle, tricycle, car, fx or taxi, bus, van, or truck. Conversely, if the vehicle involved in the accident is jeepney, it shows that during the last days of the study period, the probability of women surviving a vehicular accident dropped lower than men. Hence, males can survive higher than females if the vehicle involved in the accident is jeepney.

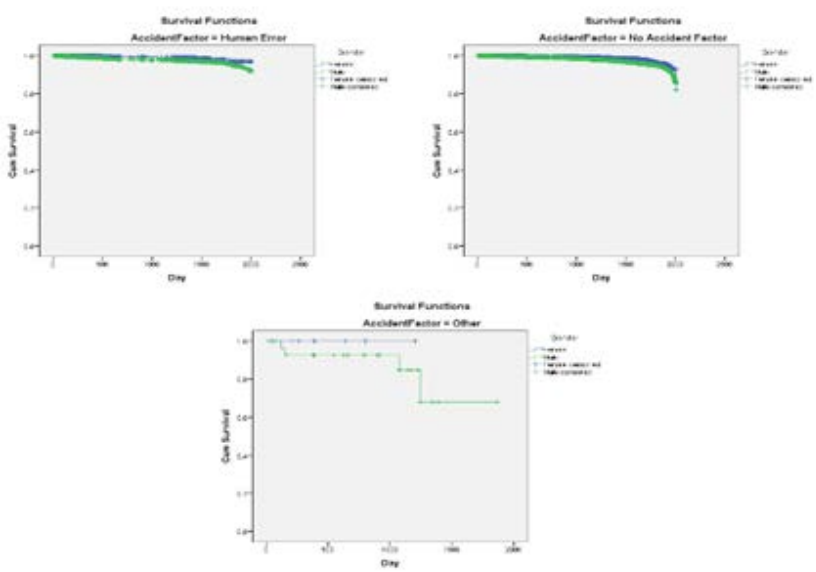

Figure 5. Survival Functions according to Gender Groups with Respect to Accident Factor.

\subsubsection{Accident Factor}

The Figure 5 shows the survival functions of persons according to their gender with respect to the accident factor of the vehicular accidents. The different accident factors that were used in the study are human error, vehicle defect, other accident factors such as slippery road, running over a piece of stone, losing of balance in driving, and passing thru red light. Though both genders have high chances of surviving the accident despite of the different accident factors, it shows that females have higher survival chances than males.

\subsubsection{Junction Type}

Figure 6 shows the survival functions of persons involved in road accidents with respect to the junction type present in the accidents. Both male and female have high survival chances whenever the accident happens not at junction, cross roads, T-junction, U-turn, rotunda, and others such as bridge or flyover, railroad track, parking area, tunnel or underpass. On the other side, men have lower survival chances than of women. At Y-junction, there are no records of death in a vehicular accident involving females. 
But it can be shown in the figure above that male still has above $50 \%$ survival chances if a vehicular accident occurs at a Y-junction.
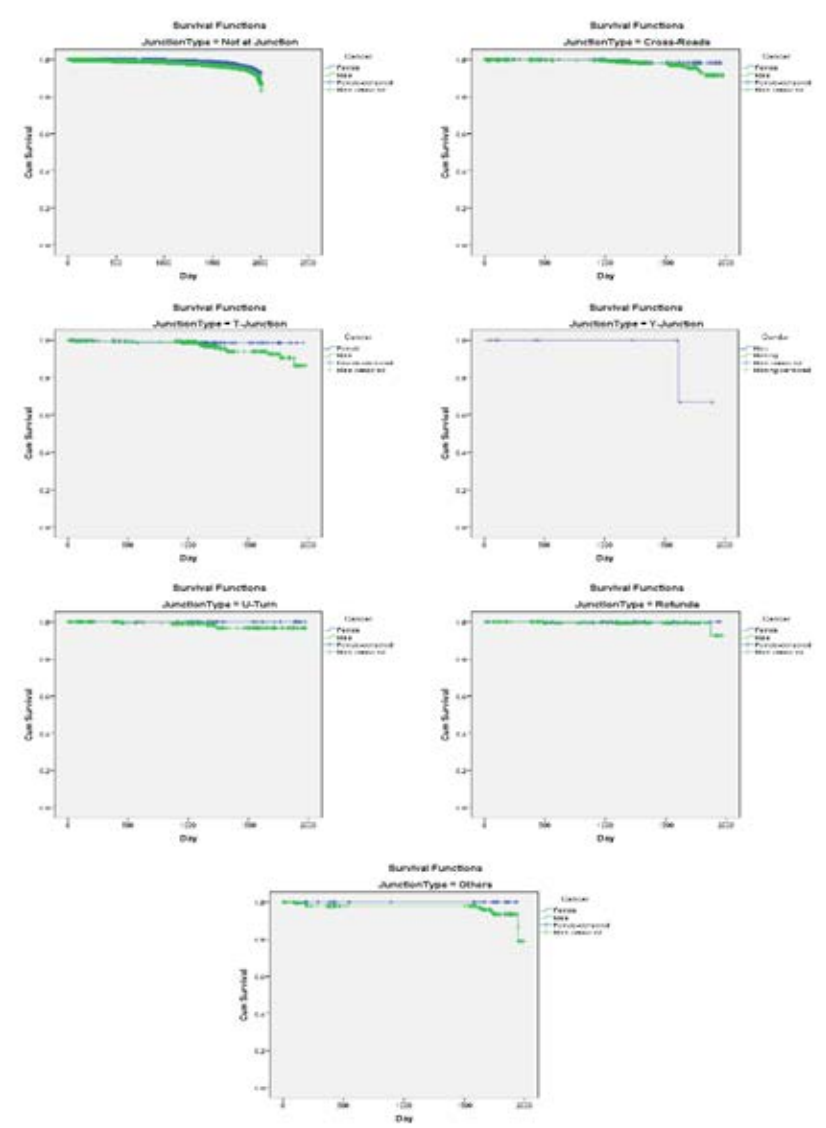

Figure 6. Survival Functions according to Gender Groups with Respect to Junction Type.
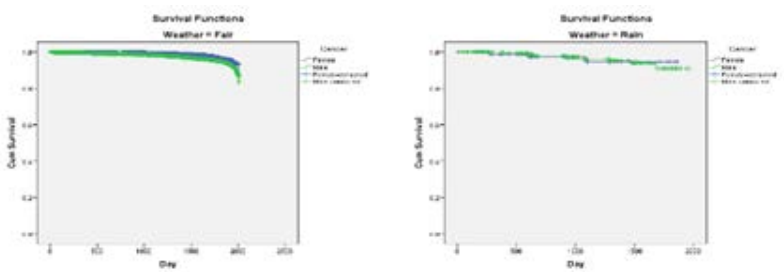

Figure 7. Survival Functions according to Gender Groups with Respect to Weather.

\subsubsection{Weather}

Figure 7 displays the survival functions of persons involved in accident according to their gender with respect to weather. Weather in this study was classified either fair or rain. Both male and female have high survival chances whatever the weather is. However, whether the road accident happens during a fair or rainy weather, it shows that women have higher survival chances than men.
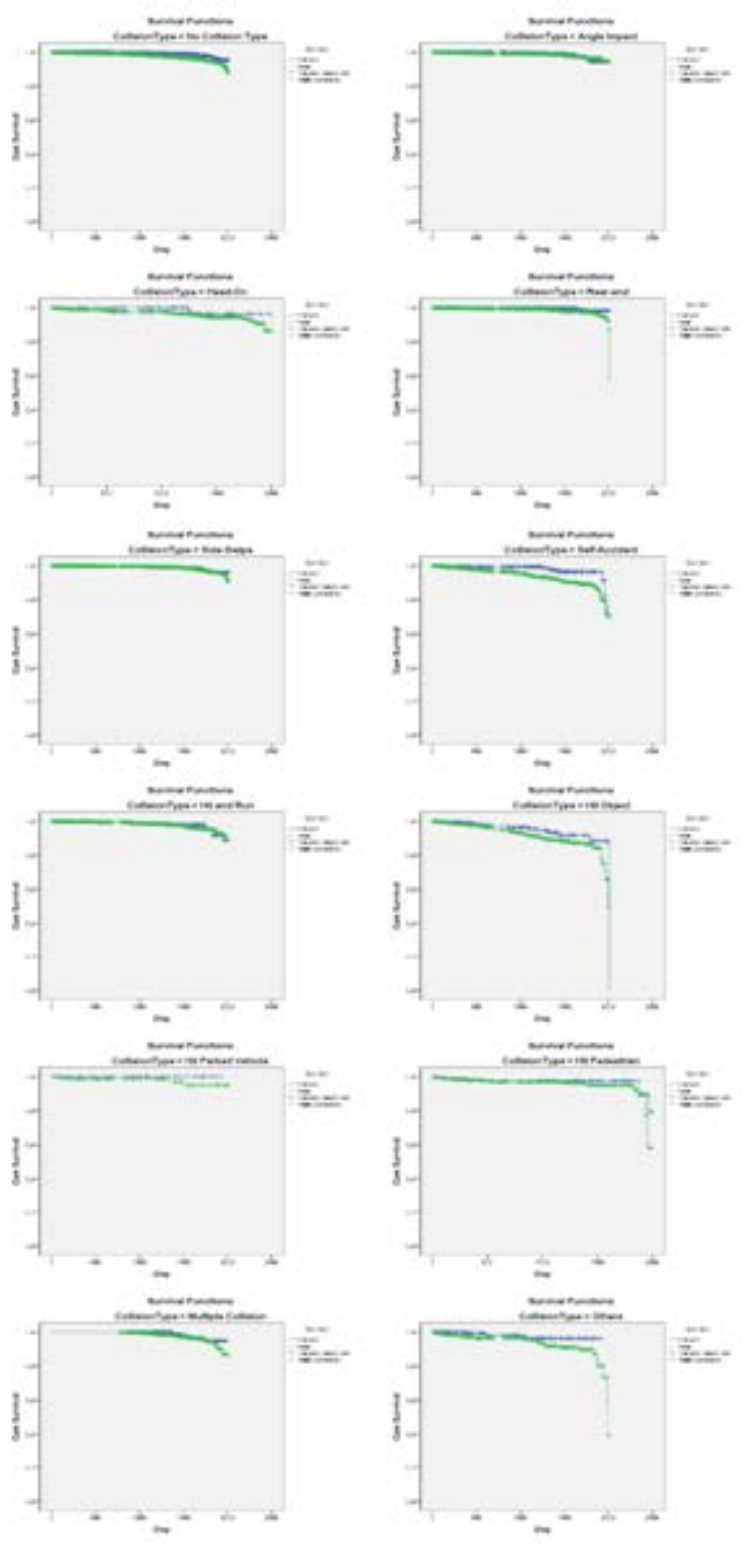

Figure 8. Survival Functions according to Gender Groups with Respect to Collision Type.

\subsubsection{Collision Type}

Figure 8 indicates the survival functions of persons according to their gender and the collision type happened in each accident. It shows that even if there is either a collision happened such as head-on, rear-end, side-swipe, hit and run, hit parked vehicle, multiple collision, and 
self-accident or not, females have higher survival chances than males. If there is an object or pedestrian that was hit, or other collision types, it shows that men have high survival chances than women, but if the collision type occurred was an angle impact, there is an almost equal survival chances for both genders.
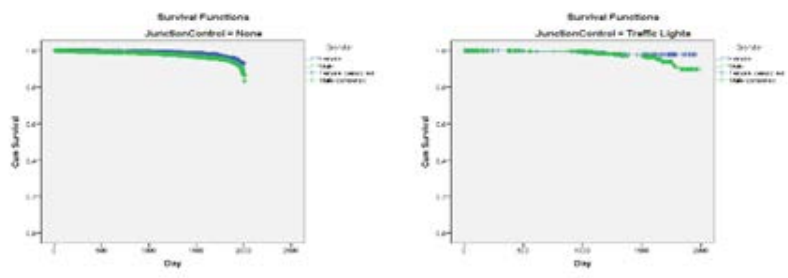

Figure 9. Survival Functions according to Gender Groups with Respect to Junction Control.

\subsubsection{Junction Control}

The Figure 9 demonstrates the survival functions of persons according to their gender with respect to the junction control involved in each vehicular accident. Both genders have high chances of survival whether there is a junction control or none. Upon comparing the survival chances of males and females, it shows that the former has better survival chances than the latter.

\subsection{Hazard Function of Persons Involved in Road Accidents with Respect to the Covariates under Cox Regression}

The researchers wanted to formulate a mathematical model that can estimate the risk of a person to die on a road accident in National Capital Region, and through Cox Regression, the hazard function has been obtained and written as:

$$
\begin{aligned}
& H(t, X)=0.00002795 e^{\left(0.0065 t+0.704 x_{1} 0.008 x_{2}+0.757 x_{3}\right)} \\
& e^{\left(-0.210 x_{4}-1.147 x_{5}-1.355 x_{6}-0.958 x_{7}-1.327 x_{8}+0.121 x_{9}\right)} \\
& e^{\left(+0.173 x_{10}+1.284 x_{11}-0.837 x_{12}-0.885 x_{13}-0.982 x_{14}-1.046 x_{15}\right)} \\
& e^{\left(-0.908 x_{16}-1.630 x_{17}-1.090 x_{18}-0.354 x_{19}-0.360 x_{20}-0.112 x_{21}\right)} \\
& e^{\left(-8.170 x_{22}+0.401 x_{23}+1.429 x_{24}-0.352 x_{25}-0.916 x_{26}+0.066 x_{27}\right)} \\
& e^{\left(0.126 x_{28}-8.611 x_{29}-0.402 x_{30}+0.524 x_{31}-0.550 x_{32}-0.605 x_{33}\right)} \\
& e^{\left(+0.944 x_{34}-0.045 x_{35}+1.378 x_{36}-0.135 x_{37}+0.620 x_{38}+0.010 x_{39}\right)} \\
& e^{\left(1.107 x_{40}\right)}
\end{aligned}
$$

where $t$ is the time the accident happened from January 1, 2012 to June 30, 2017 and $x$ are the covariates: $x_{1}$ is the weather, $x_{2}$ is the age of the persons involved in road accidents, $x_{3}$ is the gender, $x_{4}$ is the time period, $x_{5}$ is Central District, $x_{6}$ is Eastern District, $x_{7}$ is Northern District, $x_{8}$ is Southern District, $x_{9}$ is human error, $x_{10}$ is vehicle defect, $x_{11}$ is others, $x_{12}$ is bike, $x_{13}$ is motorcycle, $x_{14}$ is tricycle, $x_{15}$ is car, $x_{16}$ is jeep, $x_{17}$ is FX or taxi, $x_{18}$ is bus, $x_{19}$ is van, $x_{20}$ is truck, $x_{21}$ is cross roads, $x_{22}$ is K-junction, $x_{23}$ is T-junction, $x_{24}$ - is Y-junction, $x_{25}$ is $\mathrm{U}$-turn slot, $x_{26}$ is rotunda, $x_{27}$ is other junction type, $x_{28}$ is traffic lights, $x_{29}$ is school zone, $x_{30}$ is angle impact, $x_{31}$ is head on, $x_{32}$ is rearend, $x_{33}$ is side-swipe, $x_{34}$ is self-accident, $x_{35}$ is hit and run, $x_{36}$ is hit object, $x_{37}$ is hit parked vehicle, $x_{38}$ is hit pedestrian, $x_{39}$ is multiple collision, and $x_{40}$ refers to other collision type.

\subsection{Probability Risks of Persons Involved in Road Accidents that Lead to Death Based on the Covariates}

The probability risk of death of a person involved in a road accident is determined by the model $R(X$, Death $)=1-e^{-H(t, X)}$, where $e^{-H(t, X)}$ is the probability of survival in terms of a cumulative hazard rate function, came from Cox Proportional Hazard Rate Model and through appendices, it can be verified.

Through substitution of the Cox Proportional Hazard Rate Function into the model, the probability risk function is written as:

$$
\begin{aligned}
& R(x, \text { Death })=1-\left(e^{-0.00002795 e^{0.0065 t+0.704 x_{1}+0.008 x_{2}}}\right. \\
& e^{e^{0.757 x_{3}-0.210 x_{4}-1.147 x_{5}-1.355 x_{6}-0.958 x_{7}-1.327 x_{8}+0.121 x_{9}}} \\
& e^{e^{0.173 x_{10}+1.284 x_{11}-0.837 x_{12}-0.885 x_{13}-0.982 x_{14}-1.046 x_{15}}} \\
& e^{e^{-0.908 x_{16}-1.630 x_{17}-1.090 x_{18}-0.354 x_{19}-0.360 x_{2}-0.112 x_{21}}}
\end{aligned}
$$




$$
\begin{aligned}
& e^{e^{-8.170 x_{22}+0.401 x_{23}+1.429 x_{24}-0.352 x_{25}-0.916 x_{26}+0.066 x_{27}}} \\
& e^{e^{+0.126 x_{28}-8.611 x_{29}-0.402 x_{30}+0.524 x_{31}-0.550 x_{32}-0.605 x_{33}}} \\
& e^{e^{+0.944 x_{34}-0.045 x_{35}+1.378 x_{36}-0.135 x_{37}+0.620 x_{38}+0.010 x_{39}}} \\
& \left.e^{e^{+1.107 x_{40}}}\right) \\
& x_{1}=\left\{\begin{array}{l}
0, \text { if fair } \\
1, \text { if rain }
\end{array},\right. \\
& x_{2}=\text { age of the personinvolved, } \\
& x_{3}=\left\{\begin{array}{c}
0, \text { if female } \\
1, \text { if male }
\end{array},\right. \\
& x_{4}=\left\{\begin{array}{l}
0, \text { if } A M \\
1, \text { if } P M
\end{array},\right. \\
& x_{5}=\left\{\begin{array}{c}
0, \text { if not in Central District } \\
1, \text { if in Central District }
\end{array},\right. \\
& x_{6}=\left\{\begin{array}{c}
0, \text { if not in Eastern District } \\
1, \text { if in Eastern District }
\end{array},\right. \\
& x_{7}=\left\{\begin{array}{c}
0, \text { if not in Northern District } \\
1, \text { if in Northern District }
\end{array},\right. \\
& x_{8}=\left\{\begin{array}{c}
0, \text { if not in Southern District } \\
1, \text { if in Southern District }
\end{array},\right. \\
& x_{9}=\left\{\begin{array}{c}
0, \text { if not human error } \\
1, \text { if human error }
\end{array}\right. \\
& x_{10}=\left\{\begin{array}{c}
0, \text { if } \text { not vehicle defect } \\
1, \text { if vehicledefect }
\end{array}\right. \text {, } \\
& x_{11}=\left\{\begin{array}{c}
0, \text { if } \text { not others } \\
1, \text { if } \text { others }
\end{array},\right. \\
& x_{12}=\left\{\begin{array}{c}
0, \text { if the vehicleis not bike } \\
1, \text { if the vehicleis bike }
\end{array},\right. \\
& x_{13}=\left\{\begin{array}{c}
0, \text { if the vehicleis not motorcycle } \\
1, \text { if the vehicleis motorcycle }
\end{array},\right. \\
& x_{14}=\left\{\begin{array}{c}
0, \text { if the vehicleis not tricycle } \\
1, \text { if the vehicleis tricycle }
\end{array},\right. \\
& x_{15}=\left\{\begin{array}{c}
0, \text { if the vehicle is not car } \\
1, \text { if the vehicleis car }
\end{array},\right. \\
& x_{16}=\left\{\begin{array}{c}
0, \text { if the vehicleis not jeep } \\
1, \text { if the vehicleis jeep }
\end{array},\right. \\
& x_{17}=\left\{\begin{array}{c}
0, \text { if the vehicleis not } f x / \text { taxi } \\
1, \text { if the vehicleis } f x / \text { taxi }
\end{array},\right. \\
& x_{18}=\left\{\begin{array}{c}
0, \text { if the vehicle is not bus } \\
1, \text { if the vehicleis bus }
\end{array},\right. \\
& x_{19}=\left\{\begin{array}{c}
0, \text { if the vehicleis not van } \\
1, \text { if the vehicleis van }
\end{array},\right. \\
& x_{20}=\left\{\begin{array}{c}
0, \text { if the vehicle is not truck } \\
1, \text { if the vehicle is truck }
\end{array},\right. \\
& x_{21}=\left\{\begin{array}{c}
0, \text { if not incross roads } \\
1, \text { if in cross roads }
\end{array},\right. \\
& x_{22}=\left\{\begin{array}{c}
0, \text { if not in } K-\text { junction } \\
1, \text { if in } K-\text { junction }
\end{array},\right. \\
& x_{23}=\left\{\begin{array}{c}
0, \text { if not in } T-\text { junction } \\
1, \text { if in } T-\text { junction }
\end{array},\right. \\
& x_{24}=\left\{\begin{array}{c}
0, \text { if not in } Y-j u n c t i o n \\
1, \text { if in } Y-\text { junction }
\end{array},\right. \\
& x_{25}=\left\{\begin{array}{c}
0, \text { if not in } U-\text { turn slot } \\
1, \text { if in } U-\text { turn slot }
\end{array},\right. \\
& x_{26}=\left\{\begin{array}{c}
0, \text { if not in rotunda } \\
1, \text { if in rotunda }
\end{array},\right. \\
& x_{27}=\left\{\begin{array}{c}
0, \text { if not } \\
1, \text { if in othertypes of junction }
\end{array},\right. \\
& x_{28}=\left\{\begin{array}{l}
0, \text { if not in traffic lights } \\
1, \text { if it is in traffic lights }
\end{array},\right. \\
& x_{29}=\left\{\begin{array}{l}
0, \text { if not in school zone } \\
1, \text { if it is in school zone }
\end{array},\right. \\
& x_{30}=\left\{\begin{array}{c}
0, \text { if not angleimpact } \\
1, \text { if angle impact }
\end{array},\right.
\end{aligned}
$$




$$
\begin{aligned}
& x_{31}=\left\{\begin{array}{c}
0, \text { if not head on } \\
1, \text { if head on }
\end{array},\right. \\
& x_{32}=\left\{\begin{array}{c}
0, \text { if not rear }- \text { end } \\
1, \text { if rear }- \text { end }
\end{array},\right. \\
& x_{33}=\left\{\begin{array}{c}
0, \text { if } \text { not side }- \text { swipe } \\
1, \text { if side-swipe }
\end{array},\right. \\
& x_{34}=\left\{\begin{array}{c}
0, \text { if not self-accident } \\
1, \text { if self }- \text { accident }
\end{array},\right. \\
& x_{35}=\left\{\begin{array}{c}
0, \text { if not hit and run } \\
1, \text { if hit and run }
\end{array},\right. \\
& x_{36}=\left\{\begin{array}{c}
0, \text { if } \text { not hit object } \\
1, \text { if hit object }
\end{array},\right. \\
& x_{37}=\left\{\begin{array}{c}
0, \text { if not hit parked vehicle } \\
1, \text { if hit parked vehicle }
\end{array}\right. \text {, } \\
& x_{38}=\left\{\begin{array}{c}
0, \text { if } \text { not hit pedestrian } \\
1, \text { if hit pedestrian }
\end{array}\right. \text {, } \\
& x_{39}=\left\{\begin{array}{c}
0, \text { if } \text { not multiple collision } \\
1, \text { if multiple collision }
\end{array},\right. \\
& x_{40}=\left\{\begin{array}{c}
0, \text { if } \text { not other collision type } \\
1, \text { if } \text { other collision type }
\end{array}\right. \text {. }
\end{aligned}
$$

\section{Conclusions}

After scrutinizing the data carefully, the researchers conclude that most of the persons involved in road accidents are male. In addition to that majority of the covariates of this study reveals that women have higher chances of surviving a road accident than men. Therefore, it can also be said that female involvement in vehicular accidents is very little. Also, Kaplan-Meier Estimations showed that men have lower survival rates than women. Persons aging from 20 to 29 years old were more prone to road accidents than the other age groups which support the World Health Organization (WHO)'s Key Facts ${ }^{1}$ that road traffic injury is one of the leading causes of death among people between 15-29 years old. People riding motorcycle are also prone in road accidents which comprise a big number of the cases in this study. Overall, a person involved in a road accident has a high probability of surviving it which is above $50 \%$. Lastly, the developed probability risk of death in persons involved in road accidents determined by Cox Regression will help the government to create laws and have a strong implementation to improve the quality of the traffic situation that will lessen the chances of death furthermore the number of accidents happening in National Capital Region.

\section{Recommendations}

Based on this study, road accidents in National Capital Region is alarming due to its growing number. Then it is apparent and well perceived that issuance of professional driver licenses for public and private conveyance vehicles must be strictly observe and examined in order to realize whether the public safety and road accidents diminished or avoided. Mitigating the situations on road accidents, researchers recommend the that the drivers must undergo rigid seminars on traffic rules and regulations; Psychological and aptitude tests should be given to drivers prior to issuance of their licenses; and rules on junction and junction control should always be observed. In addition, using or referencing to the mathematical functions and probability risks generated and presented in this study could help government officials and other concerned agencies to formulate and implement laws on road safety. Future studies of this matter are also recommended.

\section{References}

1. Road Traffic Injuries: Fact Sheet. Available from: www. who.int/mediacentre/factsheets/fs358/en/. Date accessed: 07/12/2018.

2. Philippine Star. Pinoys Die Daily Road Mishaps. Available from: http://www.philstar.com/headlines /2017 /05/ 22/1702367/ 34-pinoys -die -daily -road- mishaps. Date accessed: 21/ 05/ 2017.

3. Eleventh Congress of the Philippines. Republic Act No. 8750: Seat Belts Use Act of 1999. Available from: https:// www.lawphil.net/statutes/repacts/ra1999/ra_8750_1999. html. Date accessed: 05/08/1999.

4. Fourteenth Congress of the Philippines. Republic Act No. 10054: Motorcycle Helmet Act of 2009. Manila, Philippines: The Congress. Available from: https://www.senate.gov.ph/ republic_acts/ra\%2010054.pdf. Date accessed: 23/03/2010.

5. Republic Act 4136: Land Transportation and Traffic Code. Manila, Philippines. Available from: https://www.lawphil. 
net/statutes/repacts/ra1964/ra_4136_1964.html. Date accessed: 20/06/1964.

6. Fifteenth Congress of the Philippines. Republic Act No. 10586: Anti-Drunk and Drugged Driving Act of 2013. Available from: http://www.officialgazette.gov. ph/2013/05/27/republic-act-no-10586/. Date accessed: 27/03/2013.

7. Sixteenth Congress of the Philippines. Republic Act No. 10913: Anti-Distracted Driving Act of 2015. Available from: https://www.senate.gov.ph/republic_acts/ra\%2010913.pdf. Date accessed: 21/07/2016.

8. Vehicular Accidents in NCR rise in 2016 MMDA. Available from: www.thestandard.com.ph/mobile/article/22911. Date accessed: 12/02/2017.

9. United Nations Economic and Social Commission for Asia and the Pacific. Road Safety in the Philippines: Country Report. Available from: http://www.unescap. org/sites/default/files/2.19.Philippines.pdf. Date accessed: 08/05/2013.

10. Highlights of the Philippine Population 2015 Census of Population. Available from: https://www.psa.gov.ph/ content/highlights-philippine-population-2015-censuspopulation. Date accessed: 19/05/2016.

11. Mathematical Modelling of Road Accidents in Metro Manila. Available from: http://journal.unp.edu.ph/index. php/unprj/article/view/25/UNPRJ002. Date accessed: $12 / 2014$

12. Mathematical Problems in Engineering. Available from: https://www.hindawi.com/journals/mpe/2013/547904/. Date accessed: 22/09/2013.

13. Statistical Analysis of Road Accidents Fatality in Ghana Using Poisson Regression. Available from: http:// ir.knust.edu.gh/bitstream/123456789/4544/1/FINAL\%20 THESIS\%202012\%2C\%20Oppong\%2C\%20Richard\%20 Asumadu.pdf. Date accessed: 11/2012.

14. A Logistic Regression Analysis on the Influence of Accident Factors on the Fatalities of Road Accidents in Metro Manila. Available from: https://www.ajol.info/index.php/ jfas/article/view/171476. Date accessed: 10/2018.
15. Input Output Model. United States of America: 2012. Available from: https://www.sixsigmadaily.com/input-output-model/. Date accessed: 20/08/2012.

16. Survival Analysis of Patients with End Stage Renal Disease. Available from: http://iopscience.iop.org/article/10.1088/1742-6596/622/1/012014/pdf. Date accessed: 2014.

17. Survival Analysis for the Risk of Developing Heart Attack. Available from: https://www.researchgate.net/ publication/308571152_Survival_analysis_for_the_risk_ of_developing_heart_attack. Date accessed: 09/2016.

18. In Numbers: Road crash incidents in the Philippines. Available from: https://www.rappler.com/move-ph/issues/ road-safety/166151-road-crashes-philippines-awarenesssafety. Date accessed: 14/04/2018.

19. Analysis Motorcycle Accidents on Environmental and Personal Factors. https://www.semanticscholar.org/paper/ Analysis-Motorcycle-Accidents-Based-on-and-PersonalFlores-Gotohio/3930270d2bfb4a205b2ea75cae529a63c7d 03a21. Date accessed: 2011.

20. Fatal Motorcycle Crashes: A Serious Public Health Problem in Brazil. Available from: https://www.ncbi.nlm.nih.gov/ pmc/articles/PMC3424925/. Date accessed: 22/08/2012.

21. Motorcycle accidents: Morbidity and associated factors in a city of northeast of Brazil. Available from: https://www.ncbi. nlm.nih.gov/pubmed/26591695. Date accessed: 10/2013.

22. Economic Burden of Motorcycle Accidents in Northern Ghana. Available from: https://www.researchgate.net/publication/221855911_Economic_Burden_of_Motorcycle_ Accidents_in_Northern_Ghana. Date accessed: 12/2011.

23. Effectiveness of Motorcycle Training and Licensing. Available from: https://www.sbes.vt.edu/gabler/publications/TRR-Daniello-2140-2009.pdf. Date accessed: 2009.

24. The influence of weather conditions on road safety. Available from: https:/www.swov.nl/sites/default/files/ publicaties/rapport/r-2009-09.pdf. Date accessed: 2009. 